\title{
Schiff Bazı İçeren Tek Kristal Bileşik Üzerinde X-Işınları, Spektroskopik ve Moleküler Doking Çalışmaları
}

\author{
Tuncay KARAKURT ${ }^{*}{ }^{\oplus}$, Seher MERAL ${ }^{2}$, Ayșen ALAMAN AĞAR ${ }^{3}$ \\ ${ }^{1}$ Kırşehir Ahi Evran Üniversitesi, Mühendislik-Mimarlık Fakültesi, Kimya ve Proses Mühendisliği, 40100, \\ Kırşehir, Türkiye \\ 2,30ndokuzmayıs Üniversitesi, Fen-Edebiyat Fakültesi, Kimya Bölümü, 55271, Samsun, Türkiye
}

(Alınış / Received: 21.02.2019, Kabul / Accepted: 21.05.2019, Online Yayınlanma / Published Online: 30.08.2019)

\begin{abstract}
Anahtar Kelimeler Gaussian 09W, Fenol-imin, Keto-amin, Moleküler doking

Özet: Schiff bazı ve tiyazol halkası içeren 2,2'-((1E,1'E)-(ethan-1,2dibis(azaneliden))bis(methaneliden))bis(4-(trifloromethoksi)fenol tek kristali bu çalıșmada sentezlenmiștir. Sentezlenen kristalin yapısı, IR spektroskopik ve X-ıșınları analizi teknikleri kullanılarak aydınlatılmıştır. İncelenen bileşiğin fenol-imin ve keto-amin gibi iki farklı tautomer formda olabileceği görülmüştür. Deneysel ve teorik tüm çalışmalar iki tautomer yapı üzerinde yapılmıştır. Bunun içinde bileşiğin yapısal parametreleri, GAUSSIAN 09W paket programı ve DFT/B3LYP teorisi ile optimize edildikten sonra IRC (intrinsic reaction coordinate), frontier moleküler orbital(FMO) hesaplamaları yapılmıştır. IRC çalışmasında fenol-imin formunun keto-amin formuna göre daha düşük enerjiye sahip olduğu gözlenmiş olup iki form arasındaki enerji farkı $-14.71 \mathrm{kj} / \mathrm{mol}$ olarak hesaplanmıştır. Ayrıca, fenol-imin ve keto-amin formlarına ait HOMO enerji değerleri sırasıyla, -6.31 ve -5.77 eV olarak hesaplanmıștır. Son olarak da iki tautomer yapının antifungal aktivite çalışmaları için 2RKV protein yapısına inhibitör ajan olabilmesi yönünde Moleküler Doking çalışması yapılmıştır. Bu hesaplama sonucunda fenol-imin ve keto-amin formuna ait affinite değerleri (Doking skoru) sırasıyla, $-7.7 \mathrm{ve}-7.3 \mathrm{kcal} / \mathrm{mol}$ olarak elde edilmiş olup HOMO orbital enerjileri ile affinite değerlerinin orantılı olduğu çalışmamızda gözlenmiştir.
\end{abstract}

\section{X-Rays, Spectroscopic and Molecular Docking Studies on Single Crystal Compounds Containing Schiff Base}

\section{Keywords}

Gaussian 09W, Phenol-imine, Keto-amine, Molecular docking

\begin{abstract}
E,1'E)-(ethane-1,2-diylbis(azaneylylidene))bis(methaneylylidene))bis(4(trifluoromethoxy)phenol single crystal containing Schiff base and thiazole ring was synthesized in this work. The synthesized crystalline structure was confirmed using IR spectroscopic and X-ray analysis techniques. It has been found that the analyzed compound may be two different tautomer forms such as phenol-imine and keto-amine. All experimental and theoretical studies were made on the two tautomeric structures. For this purpose, IRC (intrinsic reaction coordinate) and frontier molecular orbital (FMO) calculations were performed after the structural parameters of the title compound were optimized using GAUSSIAN 09W package program and DFT/B3LYP theory. In the IRC study, it was observed that the phenol-imine form had lower energy than the keto-amine form and the energy difference between the two forms was calculated as $-14.71 \mathrm{kj} / \mathrm{mol}$. HOMO energy values of phenol-imine and keto-amine forms was calculated as -6.31 and $-5.77 \mathrm{eV}$, respectively. Finally, Molecular Docking study was performed for the $2 \mathrm{RKV}$ protein structure to be an inhibitory agent for the antifungal activity studies of the two tautomer forms. As a result of this calculation, the affinity values of the phenol-imine and keto-amine form (Docking score) were obtained as -7.7 and $-7.3 \mathrm{kcal} / \mathrm{mol}$, respectively, and it was observed in our study that the HOMO orbital energies and the affinity values were proportional.
\end{abstract}

\section{Giriş}

Genel formülü $\mathrm{C}=\mathrm{N}$ - olan bir azometin grubu olan Schiff bazları çeşitli sübstitüe gruplar ihtiva eder [1,2].
Özellikle molekül içi $\mathrm{N}-\mathrm{H} \cdots 0$ ya da $\mathrm{O}-\mathrm{H} \cdots \mathrm{N}$ hidrojen bağı olan, sırasıyla keto-amin ve fenol-imin olarak ifade edilen iki farklı tautomer yapı ile o-hidroksi Schiff bazları oldukça ilgi çekmektedir [3-5]. Schiff 
bazlarının sentezleri ve tautomer yapılarının incelenmesi üzerine literatürde pek çok araştırma bulunmaktadır [6-8]. Özel bir izomerizm örneği olan tautomerizm, modern organik kimya, biyokimya, tıbbi kimya, farmakoloji, moleküler biyoloji çalışmalarında önemli rol oynar. Proteinler, enzimler ve reseptörler ile spesifik etkileşimleri de dahil olmak üzere birçok organik reaksiyonun ve biyokimyasal işlemin mekanizmalarının anlaşılması, yapıları içindeki tautomerizasyonun iyi bilinmesine dayanmaktadır [9]. Tautomerizm, nükleik asitlerin yapısını ve bunların mutasyonlarını kısmen açıklar [10]. Fenolimin ve keto-amin tautomer yapıları fotokromizm ve termokromizm özellikler gösterirler. Fotokromizm özeliğinin, radyasyon şiddetini ölçme ve kontrol etme, görüntü sistemleri ve optik bilgisayarlar gibi kullanım alanları mevcuttur [11]. Ayrıca, Schiff bazı içeren moleküller çeşitli endüstriyel işlemlerde kullanılmaktadır [12-15]. Aynı zamanda anti-kanser antibakteriyel, antifungal ve anti-viral etkilerinden dolayı farmakolojik özelliklere de sahiptir [16-18].

Çalışmamızda, bahsedilen bu etkiler ışığında sentezi yapılan yeni Schiff bazı olan bileşiğin yapısı, IR ve Xışınları kırınımı analizi teknikleri kullanılarak deneysel olarak aydınlatılmıştır. Deneysel çalışmalar ile karşılaştırmak amacıyla teorik olarak IRC (intrinsic reaction coordinate), frontier moleküler orbital (FMO) enerjileri ve moleküler doking simülasyon yöntemi ile de 2RKV Fusarium graminarum protein yapısı kullanılarak başlık bileşiği için inhibitör ajan adayı olabileceği yönünde çalışmalar yapılmıştır.

\section{Materyal ve Metot}

\subsection{X-Işınları kristal yapı belirleme}

Kristalin X-ışını kırınım verileri, MoKa ışını kullanılarak, Bruker APEX-II CCD [19] difraktometresi ile toplanmıştır. Kristalin yapı çözümü SHELXT-2014 [20] yazılımı ve SHELXL-2014 [21] yazılımı ile de yapı arıtım işlemi yapıldı. Arıtım işlemi sonucunda hidrojen atomları geometrik olarak yerleştirilmiş olup, aromatik $\mathrm{C}-\mathrm{H}$ ve $\mathrm{C}-\mathrm{H}_{2}$ bağ uzunlukları sırasıyla, 0.93 ve $0.97 \AA ̊$ olarak sabitlenmiştir. Yapı çözümü ve arıtım işlemleri Olex2 [22] programı ile gerçekleştirilmiştir.

\subsection{Kristalin sentezi}

2,2'-((1E,1'E) - (ethan - 1,2 dibis (azaneliden)) bis (methaneliden)) bis (4 - (trifloromethoksi) fenol etanol içinde 2 - hydroksi - 5 - (trifluoromethoksi) benzaldehid içeren ethan - 1,2 - diamin ile yoğunlaştırılarak sentezlendi. $0.0097 \mathrm{mmol} 2$ hidroksi - 5 - (triflorometoksi) benzaldehit, $20 \mathrm{~mL}$ etanol içinde çözüldü ve $20 \mathrm{~mL}$ etanol içerisinde $0.0097 \mathrm{mmol}$ etan-1,2-diamin damla damla ilave edildi. Çözelti 18 saat $90{ }^{\circ} \mathrm{C}$ 'de geri soğutma işlemi yapıldı. Sarı renkli ürün eter ile yıkanarak ve oda sıcaklığında etanolde kristalleştirildi $\left(\mathrm{C}_{18} \mathrm{H}_{14} \mathrm{~F}_{6} \mathrm{~N}_{2} \mathrm{O}_{4}\right)$ (Şekil 1). (E.N.=398K, verim 85 \%).

\subsection{Teorik hesaplama detayları}

Kristalin optimize işlemleri ve bazı parametrelerinin hesaplamaları Gaussian09 [23] programı DFT/B3LYP $[24,25]$ teorisi ve 6-31G(d) [26] baz seti kullanılarak yapılmıştır. Elde edilen sonuçlar GaussView 5 [27] programı yardımıyla görselleştirilmiştir. Moleküler doking çalışmaları ise PyRx [28] programı ile yapılmıştır.

\section{Bulgular}

\subsection{Kristalin yapısal analizi}

$\mathrm{C}_{18} \mathrm{H}_{14} \mathrm{~N}_{2} \mathrm{~F}_{6} \mathrm{O}_{4}$ molekülüne ait kristal parametreleri, veri toplama ve arıtım sürecindeki ayrıntılar Tablo 1'de, molekülün, yapı çözümü ve arıtımı sonucunda çizilmiş bir diyagramı Şekil 2a.'da ve Gaussian programında kullanılan giriş molekülü, Şekil 2b.'de verilmiştir.

Şekil 2a.'da gösterilen asimetrik birimde yarım bir molekülden meydana gelmiştir. Kristal yapı, iki $\mathrm{C}=\mathrm{N}$ grubu ve N1-C9-C9A-N1A torsiyon açısına göre bir Z,Z konfigürasyonundan meydana gelmiştir. Bileşik, triflorometoksi ve birbirine paralel olan iki fenol halkasina sahiptir.

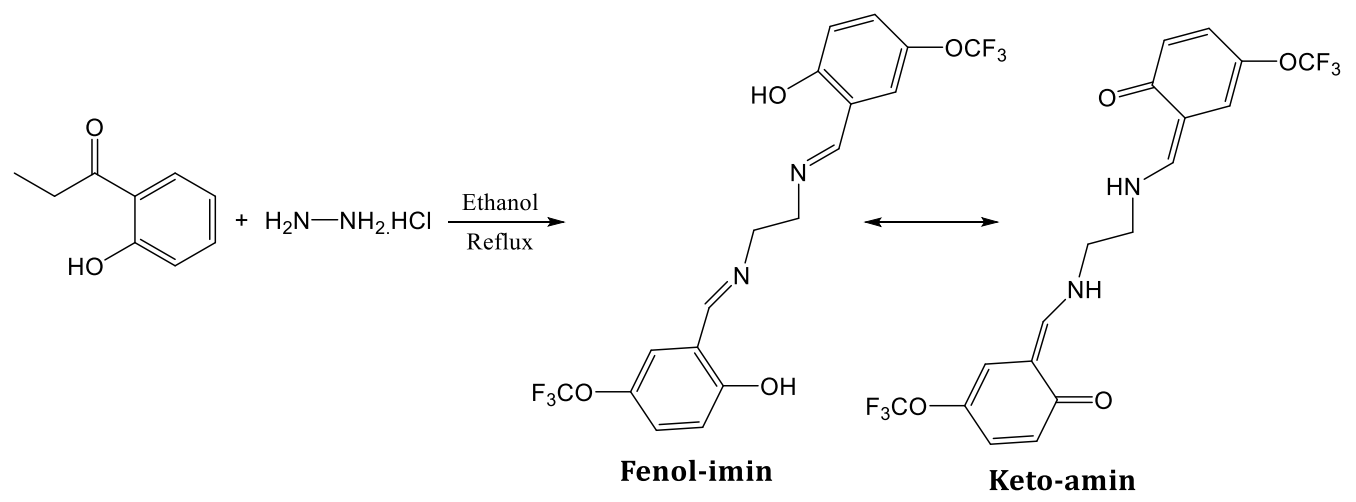

Şekil 1. Kristalin sentez aşaması 


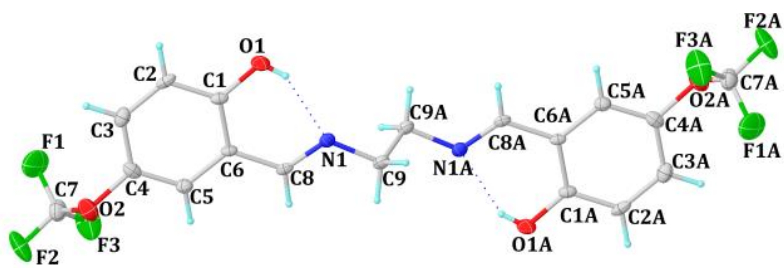

(a)

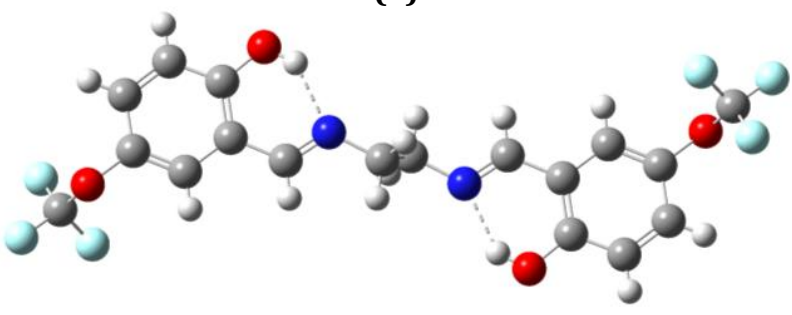

(b)

Şekil 2. $\mathrm{C}_{18} \mathrm{H}_{14} \mathrm{~N}_{2} \mathrm{~F}_{6} \mathrm{O}_{4}$ Kristalinin fenol-imin formundaki (a) deneysel (b) hesaplanan șekilleri

Tablo 1. $\mathrm{C}_{18} \mathrm{H}_{14} \mathrm{~N}_{2} \mathrm{~F}_{6} \mathrm{O}_{4}$ Kristaline ait veri toplama ve arıtım değerleri

\begin{tabular}{|c|c|}
\hline Kristal Formu & Fenol-imin \\
\hline Kimyasal Formül & $\mathrm{C}_{18} \mathrm{H}_{14} \mathrm{~F}_{6} \mathrm{~N}_{2} \mathrm{O}_{4}$ \\
\hline Molekül Ağırlığı & 436.31 \\
\hline Sıcaklık/K & $293(2)$ \\
\hline Kristal sistem & Monoklinik \\
\hline Uzay grubu & $\mathrm{P} 2{ }_{1} / \mathrm{c}$ \\
\hline $\mathbf{a} / \AA$ & $19.774(4)$ \\
\hline b/Å & $7.6285(15)$ \\
\hline c/Å & $6.1502(10)$ \\
\hline$\alpha /^{\circ}$ & 90 \\
\hline$\beta /{ }^{\circ}$ & $91.279(6)$ \\
\hline$\gamma /{ }^{\circ}$ & 90 \\
\hline $\begin{array}{l}\text { V/ } \AA^{3} \text { (Birim Hücrenin } \\
\text { hacmi) }\end{array}$ & $927.5(3)$ \\
\hline $\begin{array}{l}\text { Z(Birim Hücredeki } \\
\text { Molekül Sayısı) }\end{array}$ & 2 \\
\hline $\begin{array}{l}D / \mathrm{g} / \mathrm{cm}^{3} \text { (Hesaplanan } \\
\text { Yoğunluk) }\end{array}$ & 1.562 \\
\hline $\begin{array}{l}\mu / \text { mm }^{-1} \text { (çizgisel } \\
\text { soğurma katsayısı) }\end{array}$ & 0.150 \\
\hline $\mathbf{F}(000)$ & 444.0 \\
\hline Kristal boyutu/mm³ & $0.09 \times 0.08 \times 0.04$ \\
\hline Radyasyon & $\operatorname{MoK} \alpha(\lambda=0.71073)$ \\
\hline$\Theta$ aralığı/ ${ }^{\circ}$ & 6.182 to 49.994 \\
\hline İndeks Aralığı & $\begin{array}{l}-23 \leq \mathrm{h} \leq 23,-9 \leq \mathrm{k} \leq 9,- \\
6 \leq \mathrm{l} \leq 7\end{array}$ \\
\hline Toplanan Yansıma & 14267 \\
\hline Bağımsız yansıma & $\begin{array}{l}1594\left[\mathrm{R}_{\text {int }}=0.0746,\right. \\
\left.\mathrm{R}_{\text {sigma }}=0.0471\right]\end{array}$ \\
\hline $\begin{array}{l}\text { Parametre sayısı } \\
\text { Goodness-of-fit on }\end{array}$ & $1594 / 0 / 140$ \\
\hline $\begin{array}{l}F^{2} \text { (Yerleşim } \\
\text { Doğrulama Faktörü) }\end{array}$ & 1.104 \\
\hline $\begin{array}{l}\text { Sonuç } R \text { indeksi }[I>=2 \sigma \\
\text { (I)] }\end{array}$ & $\begin{array}{l}\mathrm{R}_{1}=0.1244, \mathrm{wR}_{2}= \\
0.2873\end{array}$ \\
\hline $\begin{array}{l}\text { Sonuç R indeksi [Tüm } \\
\text { data] }\end{array}$ & $\begin{array}{l}\mathrm{R}_{1}=0.1693, \mathrm{wR}_{2}= \\
0.3146\end{array}$ \\
\hline$\Delta \sigma_{\max }, \Delta \sigma_{\min }\left(\mathrm{e} / \AA^{3}\right)$ & $0.50 /-0.34$ \\
\hline CCDC Numarası & 1888748 \\
\hline
\end{tabular}

Deneysel ve hesaplanan bağ uzunlukları, bağ açıları, torsiyon açıları Tablo 3'de gösterilmiştir. C1-01 bağ uzunluğu deneysel olarak 1.33(8) Å gözlenmiş olup literatür değeriyle 1.34(15) [29] uyum içerisindedir. C8=N1, C6-C8, C5-C6 ve C1-C2 bağ uzunlukları, deneysel olarak 1.26(7), 1.45(8), 1.39(8) ve 1.38(9) $\AA$ olarak gözlenmiștir. $\mathrm{Bu}$ uzunluklar literatürde sirasiyla, 1.28 (14), 1.49 (14), 1.39 (15) ve $1.39(16) \AA$ [30] ve 1.279 (3), 1.486 (3), 1.399 (3) ve 1.383 (3) [31] olarak verilmiştir. C1-01 tek bağ karakteri gösterirken C8=N1 bağ uzunluğu çift bağ karakteri göstermiștir. Bu uzunluklar molekülün fenol-imin formunu benimsediğini desteklemektedir. Şekil 3a'da asimetrik birimde keto-amin formundaki kristalin elektron yoğunluğu fark haritasına bakıldığında, 01 atomu yanında bulunan mavi renkli bölgede proton eksikliği olduğunu, N1 atomuna bağlı olan H1 atomu yanındaki kırmızı bölge ise proton fazlalığı olduğunu göstermektedir [32]. Bu yüzden, H1 atomunun ketoamin formunda yanlış bir pozisyonda olduğu, Şekil 3b'de ise fenol-imin formundaki kristalde 01 ve N1 atomları etrafında proton eksikliği ya da fazlalığı görülmediğinden, $\mathrm{H} 1$ atomunun doğru konumlandığı söylenebilir.

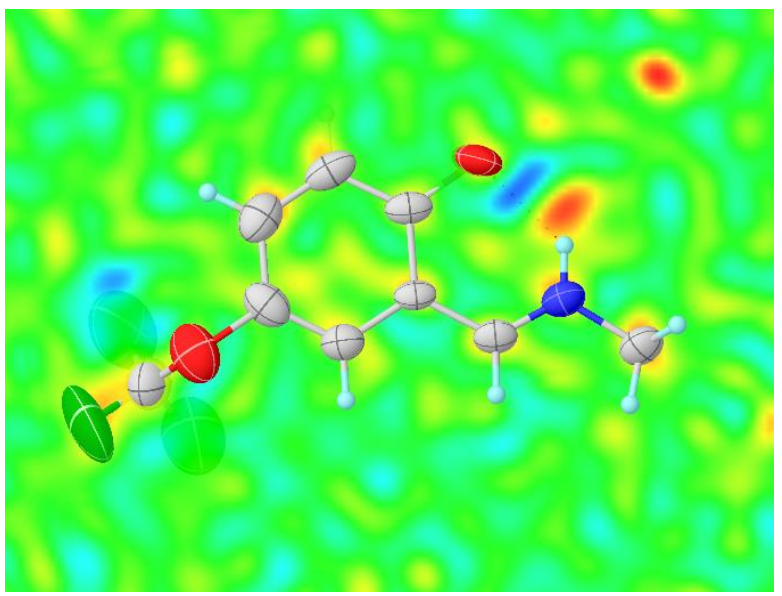

(a)

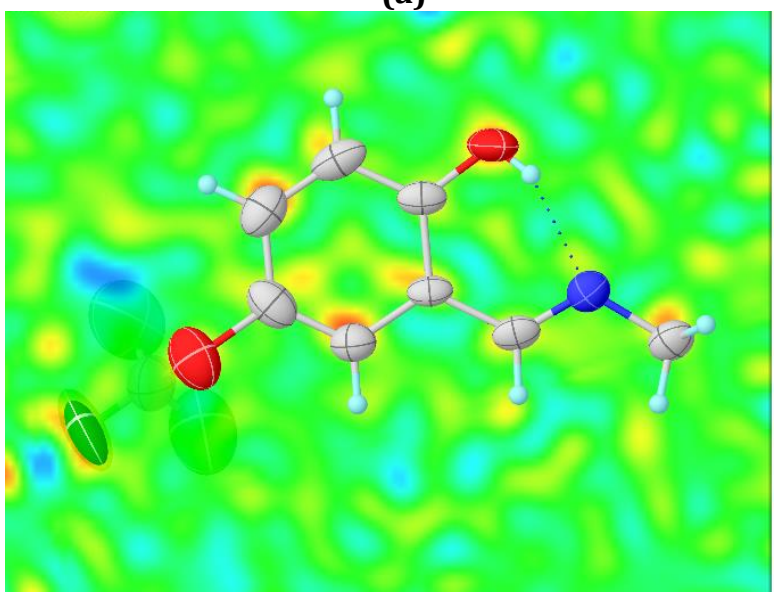

(b)

Şekil 3. İki tautomer yapının elektron yoğunluk fark haritasi.

Kristalde molekül içi O-H $\cdots \mathrm{N}$ tipi molekül içi hidrojen bağı, bir tane de moleküller arası C-H...F klasik hidrojen bağı olduğu belirlenmiştir. C3 atomu (simetri 
kodu: $\mathrm{x}, \mathrm{y}, \mathrm{z}$ ) donör gibi davranarak F1 atomu (simetri kodu: $\mathrm{x}, \mathrm{y},-1+\mathrm{z})$ ile $\mathrm{C}-\mathrm{H} \cdots \mathrm{F}$ hidrojen bağ oluşturmaktadır. Oluşan bu hidrojen bağları C(5) zincir motifli dimerleri meydana getirmiştir. Ayrıca kristal içindeki moleküler düzenlenişte $\mathrm{C}-\mathrm{H} \cdots \mathrm{Cg}(\pi-$ halka) etkileşmesi de mevcuttur. Bu etkileşimler, (x, y, z) konumundaki C5 atomunun, fenol halkasının kütle merkezi ile [kütle merkezi kesirsel koordinatları: $0.25908(14), 0.5037(3), 0.5573(4)]$ yapılmıștır. Tablo 2'de bu etkileşimlere ait simetri bilgileri verilmiştir.

Tablo 2. Fenol-imin formundaki kristal için Hidrojen Bağı ve $\pi$-halka etkileşimlerine ait parametreler

\begin{tabular}{|c|c|c|c|c|}
\hline D-H....A (̊) & D-H (A) & H....A (风) & D....A (A) & D-H....A ( $\left(^{\circ}\right)$ \\
\hline$\overline{\mathrm{O} 1-\mathrm{H} 1 \ldots \mathrm{N} 1}$ & $0.70(6)$ & $2.02(5)$ & $2.63(7)$ & $143(6)$ \\
\hline C $3-\mathrm{H} 3 \ldots \mathrm{F} 1^{\mathrm{i}}$ & 0.93 & 2.52 & $3.364(10)$ & 150 \\
\hline C5-H5 ....Cg(1) ${ }^{i i}$ & 0.93 & 2.97 & $3.668(7)$ & 133 \\
\hline
\end{tabular}

Simetri kodları: (i) $\mathrm{x}, \mathrm{y},-1+\mathrm{z}$; (ii) $\mathrm{x}, 3 / 2-\mathrm{y}, 1 / 2+\mathrm{z}$ Kristalin fenol-imin formuna ait birim hücre içerisindeki C-H...F etkileşimleri Şekil 4 ve C-H...Cg etkileşimleri ise Şekil 5'de gösterilmiştir.

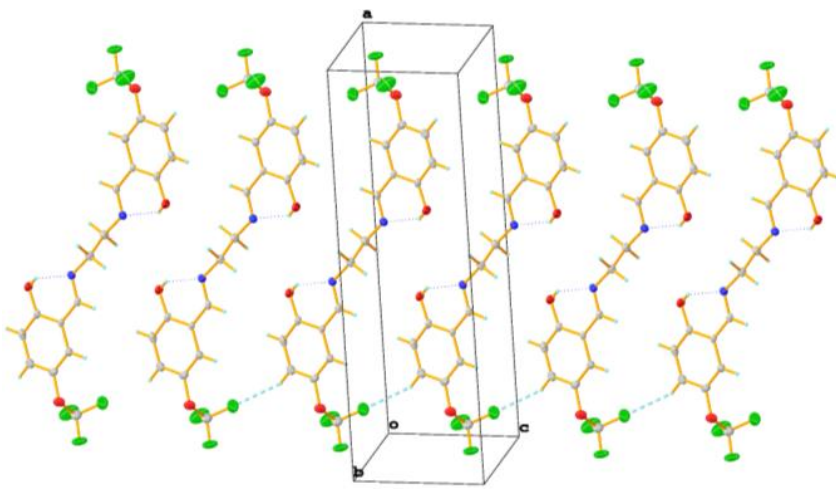

Şekil 4. $\mathrm{C}_{18} \mathrm{H}_{14} \mathrm{~N}_{2} \mathrm{~F}_{6} \mathrm{O}_{4}$ Kristalinin fenol-imin formundaki C$\mathrm{H} \cdots \mathrm{F}$ etkileşimleri ile kendini tekrarlaması

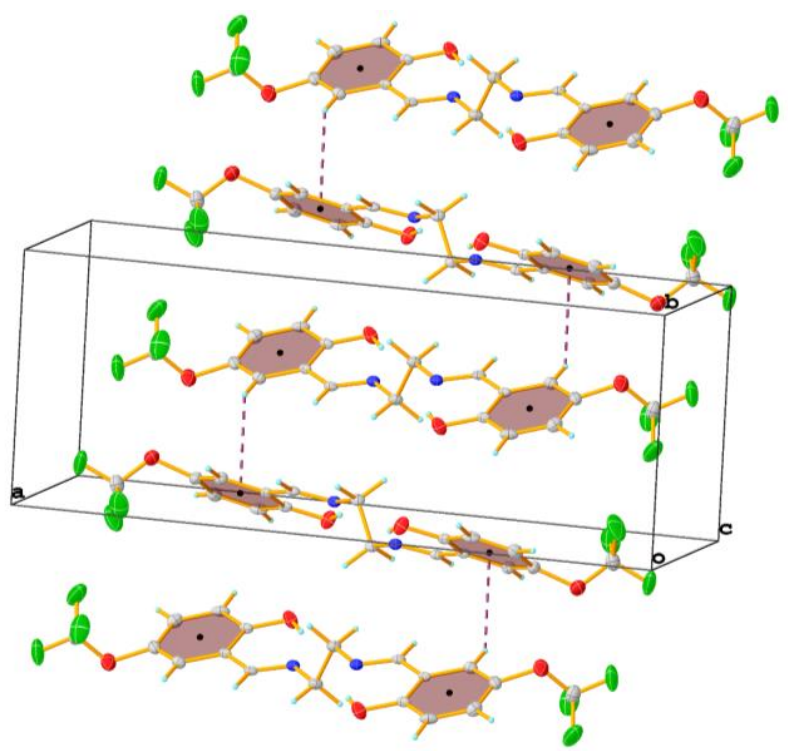

Şekil 5. Fenol-imin formundaki kristalin $\mathrm{C}-\mathrm{H} \cdots \mathrm{Cg}$ etkileşimleri ile paketlenmesi

Gaussian programı ile 3 boyutlu potansiyel enerji yüzeyi taraması (PES) (Şekil 6) sonucu ortaya çıkan 4 minimum enerjiye karşıllk gelen konformasyonlardan elde edilen optimize moleküllerden minimum enerjiye sahip olan en kararlı molekül de Şekil 2b'de gösterilmiştir. PES analizi için, moleküle ait $\theta_{1}$ (C7-O2C4-C5) ve $\theta_{2}$ (N1-C8-C6-C5) dihedral açları $180 /+180^{\circ}$ aralığında $20^{\circ}$ 'lik açllarla değiștirilerek her bir adımda tek nokta enerjileri hesaplandı. Kararlı molekülün $\theta_{1}$ ve $\theta_{2}$ dihedral açıları sırasıyla $179.9^{\circ}$ ve $90.1^{\circ}$ olarak belirlenmiştir.

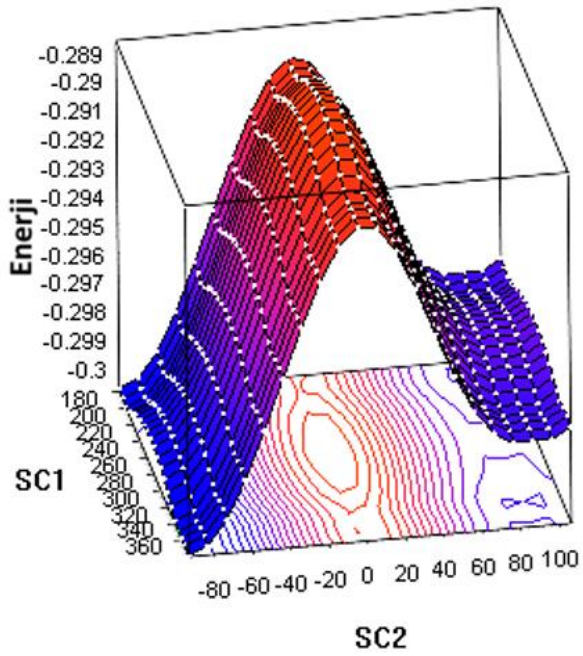

Sekil 6. Fenol-imin formuna ait 3 boyutlu PES analizi haritası

İki tautomer forma ait olan deneysel ve teorik hesaplama sonuçları karşılaştırmalı olarak Tablo 3'de listelenmiştir.

\subsection{Tautomerizm (IRC)}

Calıștığımız molekülün iki tautomer yapıya sahip olup olmadığını yapmış olduğumuz teorik hesaplamalar ile inceledik. İki tautomer yapının ve molekülün geçiş durumuna (TS) ait bazı yapı parametreler hesaplanmıștır. Tablo 4'de iki tautomer yapıya ait enerjiler, ileri ve geri yönlü reaksiyonlara ait aktivasyon enerjileri verilmiştir. Molekülün geçiş durumuna ait imajiner titreşim frekansı $1213 \mathrm{i} \mathrm{cm}-1$ olarak hesaplanmış olup geçiş durumunun doğruluğu da böylece ispatlanmıștır. Keto-amin ve fenol-imin tautomer formlar, molekül içi proton transferi reaksiyonu ile birbirlerine dönüşmeleri mümkündür. $\mathrm{O}$ atomundan $\mathrm{N}$ atomuna ya da $\mathrm{N}$ atomundan $\mathrm{O}$ atomuna doğru hidrojen atomunun göçü nedeni ile yapı içinde bazı değişiklikler meydana gelebilir. Fenol-imin formundan keto-amin formuna doğru proton transferi gerçekleşirken $\mathrm{O}-\mathrm{H}$ bağ uzunluğu artarak kopar. $\mathrm{O}$ atomundan kopan $\mathrm{H}$ atomu $\mathrm{N}$ atomuna bağlanarak proton transferi süreci tamamlanır. Tablo 5'e bakıldığında, bu süreç gerçekleşirken, N1-C8 ve C1-C6 bağ uzunlukları artarken 01-C1, C6-C8 bağ uzunlukları azalmıştır. Yapısal açıdan bakıldığında, bütün sonuçlar, geçiş durumunun, keto-amin formundan daha çok fenolimin formuna benzediğini göstermiştir.

Proton transferi işleminin enerji profilinin gösterildiği Şekil 7'de, iki tautomer yapı arasındaki enerji farkı $14.71 \mathrm{kj} / \mathrm{mol}$ olarak hesaplanmış olup fenol-imin 
formunun keto-amin formuna göre daha stabil olduğu görülmektedir.

Tablo 3. Kristalinin iki tautomer formuna ait deneysel ve teorik parametreler

\begin{tabular}{|c|c|c|c|c|}
\hline $\begin{array}{c}\text { Bağ } \\
\begin{array}{c}\text { Uzunlukları } \\
(\AA \AA)\end{array} \\
\end{array}$ & $\begin{array}{c}\text { Deneysel } \\
\text { (Fenol- } \\
\text { imin) }\end{array}$ & $\begin{array}{l}\text { Deneysel } \\
\text { (Keto- } \\
\text { amin) }\end{array}$ & $\begin{array}{c}\text { DFT } \\
\text { (Fenol- } \\
\text { imin) }\end{array}$ & $\begin{array}{c}\text { DFT } \\
\text { (Keto- } \\
\text { amin) }\end{array}$ \\
\hline 01-C1 & $1.33(8)$ & $\begin{array}{l}1.339(7) \\
1.246(7)\end{array}$ & 1.34 & 1.26 \\
\hline N1-C8 & $1.26(7)$ & $1.246(7)$ & 1.26 & 1.32 \\
\hline $\mathrm{N} 1-\mathrm{C} 9$ & 1.46(7) & $1.453(7)$ & 1.45 & 1.44 \\
\hline F2-C7 & $1.25(1)$ & $1.249(8)$ & 1.40 & 1.40 \\
\hline C9-C9A & $1.48(9)$ & $1.478(7)$ & 1.35 & 1.35 \\
\hline C8-C6 & $1.45(8)$ & $1.445(7)$ & 1.45 & 1.39 \\
\hline C6-C1 & $1.40(7)$ & $1.400(6)$ & 1.42 & 1.46 \\
\hline C6-C5 & $1.39(8)$ & $1.394(7)$ & 1.40 & 1.42 \\
\hline $\mathrm{C} 1-\mathrm{C} 2$ & $1.38(8)$ & $1.389(8)$ & 1.40 & 1.44 \\
\hline O2-C7 & $1.30(1)$ & $1.301(8)$ & 1.34 & 1.36 \\
\hline C5-C4 & $1.36(9)$ & $1.351(8)$ & 1.38 & 1.36 \\
\hline $\mathrm{C} 4-\mathrm{C} 3$ & $1.40(1)$ & $1.399(9)$ & 1.39 & 1.42 \\
\hline \multicolumn{5}{|c|}{ Bağ Açıları (o) } \\
\hline C8-N1-C9 & $119.0(5)$ & $120.4(4)$ & 119.3 & 125.3 \\
\hline $\mathrm{C} 7-02-\mathrm{C} 4$ & $117.5(6)$ & $118.0(5)$ & 116.8 & 116.7 \\
\hline N1-C8-C6 & $123.5(5)$ & $124.0(5)$ & 122.5 & 122.9 \\
\hline C1-C6-C8 & $121.2(5)$ & $121.1(4)$ & 121.2 & 119.4 \\
\hline C5-C6-C8 & $119.8(5)$ & $119.8(4)$ & 119.5 & 119.7 \\
\hline C5-C6-C1 & $119.0(5)$ & $119.1(4)$ & 119.2 & 120.7 \\
\hline 01-C1-C6 & $121.7(5)$ & $120.9(4)$ & 122.1 & 122.2 \\
\hline 01-C1-C2 & $118.6(6)$ & $119.7(5)$ & 118.4 & 121.8 \\
\hline C2-C1-C6 & $119.7(5)$ & $119.4(5)$ & 119.4 & 115.9 \\
\hline N1-C9-C9A & $109.8(5)$ & $110.4(4)$ & 110.2 & 111.4 \\
\hline $\mathrm{C} 4-\mathrm{C} 5-\mathrm{C} 6$ & $120.8(6)$ & $120.6(5)$ & 120.1 & 119.6 \\
\hline O2-C7-F1 & $110.8(8)$ & $115.7(7)$ & 112.4 & 112.5 \\
\hline F2-C7-F1 & $106.9(8)$ & $108.9(7)$ & 108.6 & 108.6 \\
\hline \multicolumn{5}{|c|}{ Dihedral Açılar (o) } \\
\hline C8-C6-C1-01 & $0.2(9)$ & $-0.4(7)$ & -0.0 & 0.2 \\
\hline N1-C8-C6-C5 & $-177.1(6)$ & $-177.4(5)$ & 179.8 & 179.3 \\
\hline C5-C6-C1-01 & $178.5(6)$ & $178.5(4)$ & -179.8 & -179.8 \\
\hline C7- O2-C4-C5 & $97.4(8)$ & $-97.5(7)$ & 90.4 & 91.1 \\
\hline C8-N1-C9-C9A & $-114.8(6)$ & $114.9(5)$ & -121.4 & -107.7 \\
\hline
\end{tabular}

Tablo 4'e bakıldığında, geçiş durumu enerjisinin, fenol-imin formuna göre relativ enerjisi $18.14 \mathrm{kj} / \mathrm{mol}$ iken, geri reaksiyon bariyer enerjisi $3.43 \mathrm{kj} / \mathrm{mol}$ olarak hesaplanmıştır. Bu sonuca göre ileri yönlü proton transferinin gerçekleşmesi için yüksek bir enerjiye ihtiyaç varken geri yönlü reaksiyon için ise daha düşük bir enerjiye ihtiyaç vardır. Bu durum, geri yönlü proton transferinin, ileri yönlü proton transferinden çok daha kolay olacağını göstermektedir [32].

\subsection{Spektroskopik çalışmalar}

4000-400 $\mathrm{cm}^{-1}$ aralığında ölçülen IR spektrumu Şekil 8a'da ve teorik olarak hesaplanan IR titreșim frekans spektrumu da Şekil 8b'de verilmiştir. Molekül, C1 nokta grubu simetrisinde 42 atoma ve 126 temel titreşim frekansına sahiptir. Tüm hesaplamalar fenolimin formu için DFT(B3LYP/6-31G(d)) teoremi kullanılarak yapılmıştır.

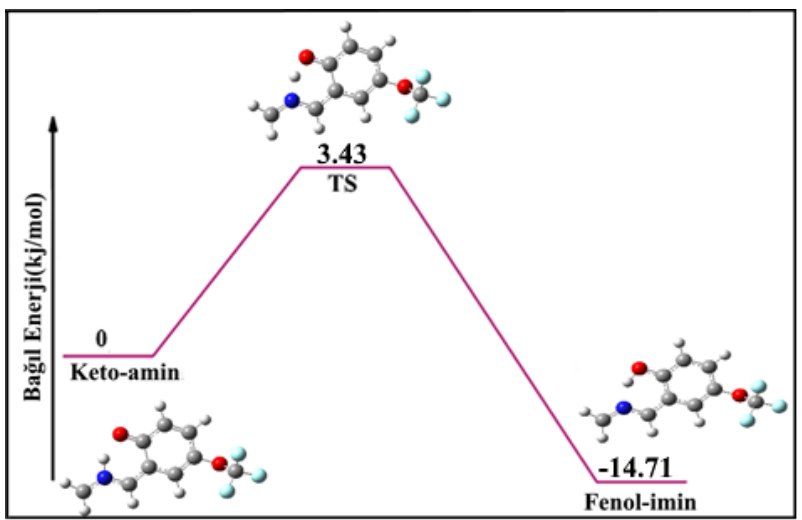

Şekil 7. Fenol-imin ve keto-amin tautomerlerinin bağll enerji diyagramı (asimetrik birim)

3550-3200 $\mathrm{cm}^{-1}$ arasında çlkması beklenen -OH piki, O-H...N hidrojen bağı dolayısıyla spektrumda deneysel olarak gözlenememiştir. Bu pik $3048 \mathrm{~cm}^{-1}$ olarak hesaplanmıştır. Hidrojen bağı varlığında bu gruba ait gerilme titreșim frekans değerleri azalırken bükülme titreșim frekans değerleri ise artmaktadır [29]. O-H moduna ait düzlem içi bükülme titreşim piki, $1490 \mathrm{~cm}$ 1 gözlenmiştir. Literatürde ise bu pikin değeri 1494 $\mathrm{cm}^{-1}$ [33] ve 1409 [34] $\mathrm{cm}^{-1}$ olarak gözlenmiştir. Bu mod teorik olarak $1418 \mathrm{~cm}^{-1}$ olarak hesaplanmıştır. Düzlem dışı açı bükülme titreşim frekansı $780 \mathrm{~cm}^{-1}$ olarak gözlenirken $786 \mathrm{~cm}^{-1}$ olarak da hesaplanmıștır.

Schiff bazlarına ait karakteristik imin piki 1600-1700 $\mathrm{cm}^{-1}$ bölgesinde karşılașılmaktadır. Molekülde bulunan imin $(\mathrm{C}=\mathrm{N})$ grubuna ait pik $1635 \mathrm{~cm}^{-1} \mathrm{de}$ gözlenmiştir. Aromatik $\mathrm{C}=\mathrm{C}$ bağlarına ait pikler ise 1489 ve $1580 \mathrm{~cm}^{-1}$ 'de gözlenmiştir. OH grubunun bağlı olduğu fenolik $\mathrm{C}-\mathrm{O}$ piki ise $1260 \mathrm{~cm}^{-1}$ 'de ve $\mathrm{CF}_{3}$ pikleri ise $1150 \mathrm{~cm}^{-1}$ de oldukça şiddetli olarak gözlenmiştir.

\subsection{Frontier moleküler orbitaller (FMOs)}

Bir moleküldeki en önemli orbitaller HOMO ve LUMO olarak adlandırılan sınır moleküler orbitallerdir. $\mathrm{Bu}$ orbitaller molekül içi etkileşmeleri betimlerler. HOMO ve LUMO orbitalleri arasındaki enerji farkı moleküllerin kimyasal kararlılığının bir ölçüsü olup moleküllerin kimyasal ve spektroskopik özelliklerinin belirlenmesinde büyük rol oynar [35].

Tablo 4. İki tautomer forma ait aktivasyon (Ea) ve geçiş durumu (TS) enerjileri

\begin{tabular}{llllll}
\hline $\begin{array}{l}\text { Fenol- } \\
\text { imin(a.u.) }\end{array}$ & $\begin{array}{l}\text { Keto- } \\
\text { amin(a.u.) }\end{array}$ & TS (a.u.) & $\Delta \mathbf{E}(\mathrm{kJ} / \mathrm{mol})$ & $\mathbf{E} \boldsymbol{a}(\mathrm{i})(\mathrm{kJ} / \mathrm{mol})$ & $\mathbf{E} \boldsymbol{a}(\mathrm{g})(\mathrm{kJ} / \mathrm{mol})$ \\
\hline- & - & - & -14.71 & 18.14 & 3.43 \\
\hline 851,8465364 & 851,8409331 & 851,8396259 & & \\
\hline
\end{tabular}

$\Delta E=\mathrm{E}_{\text {fenol}}-\mathrm{E}_{k e t o}, \mathrm{E}_{\mathrm{a}}(\mathrm{i})=$ ileri yönlü aktivasyon enerjisi, $\mathrm{E}_{\mathrm{a}}(\mathrm{g})$ = geri yönlü aktivasyon enerjisi 
Tablo 5. Proton transferi süreci sonunda bağ uzunluklarının değișimi

\begin{tabular}{lll}
\hline Bağ Uzunlukları $(\AA)$ & Fenol-imin & Keto-amin \\
\hline N1-C8 & 1.347 & 1.351 \\
C1-C6 & 1.416 & 1.425 \\
01-C1 & 1.331 & 1.268 \\
C6-C8 & 1.426 & 1.402 \\
\hline
\end{tabular}

$\mathrm{Bu}$ iki orbital arasındaki enerji farkı ( $\left.\triangle \mathrm{E}=\mathrm{E}_{\text {LUмо }}-\mathrm{E}_{\text {номо }}\right)$, fenol-imin formu için $4.42 \mathrm{eV}$, keto-amin formu için ise $3.43 \mathrm{eV}$ olarak hesaplanmış olup fenol-imin formu için hesaplanan değerin keto-amin formuna göre daha büyük olması daha kararlı yapıda olduğunu gösterir [30]. Şekil 9'da, HOMO ve LUMO orbitallerinin yerelleştiği bölgeler gösterilmiştir. FMO orbital (HOMO ve LUMO) enerjileri, biyolojik aktivitelerde özellikle ligant reseptör etkileşimlerini açılkamak için kullanılmaktadır [36]. HOMO enerjisi yüksek ligant molekülü ile reseptör molekülünün daha stabilize edici etkileşimlere neden olduğu ve deneysel aktivite çalışmaları ile daha uyumlu olduğu bildirilmiștir [37]. Çalıştığımız molekülün fenol-imin formuna ait HOMO enerjisinin keto-amin formuna göre yüksek çıkması, olası bir reseptör ligant olarak doking çalışmalarında daha stabilize etkileşimler göstereceği söylenebilir.

\subsection{Moleküler doking çalışması}

Moleküler doking çalışması Autodock Vina yazılımı kullanılarak yapılmıștır. Doking veri giriși dosyalarını oluşturmak için PyRx, Reseptör-ligand etkileşimlerini göstermek için de Discovery Studio Visualizer 2017 programları kullanılmıştır. Moleküler doking çalışmaları 1.6 Å çözünürlügüne sahip Koenzim A ve T2 mikotoksin (ZBA) ile kompleks halinde olan trikotesen 3-0-asetiltransferaz (PDB ID: 2RKV) 'nin Xışını kristal yapıları kullanılarak gerçekleştirildi. Hesaplamalara geçmeden önce 2RKV'nin kristal yapısı ve fenol-imin ve keto-amin bileşikleri, PyRx paketinde yer alan protein ve ligant hazırlama sihirbazları kullanılarak hazır hale getirildi. Doking ișlemi öncesi ilk olarak 2RKV protein yapısından doğal ligand (ZBA) haricindeki su ve heteroatomlar çlkarıldıktan sonra hidrojen atomları ve Gasteiger yükleri ilave edilmiştir.

Moleküler doking çalışmaları, sentezlenen bileşiklerin olası bağlanma modlarını görmek için yapılmıștır. İki ligant yapının (fenol-imin ve keto-amin) ve doğal ligant ZBA'nın doking skorları (affinite) ve HOMO enerjileri Tablo 6'da, hedef proteinin aktif bağlanma bölgelerine doking işlemleri Şekil 10-12'de verilmiştir.

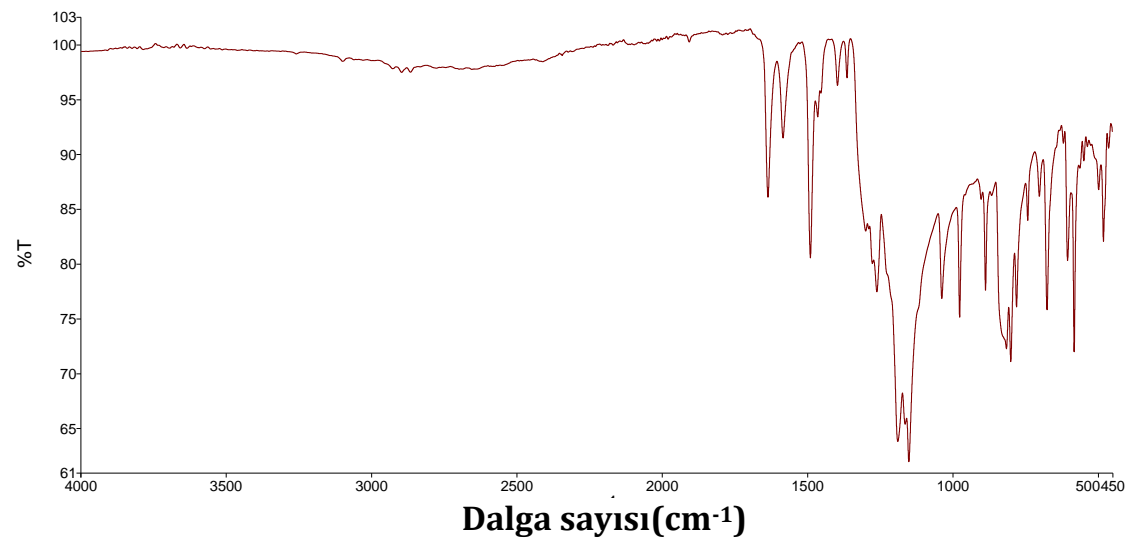

(a)

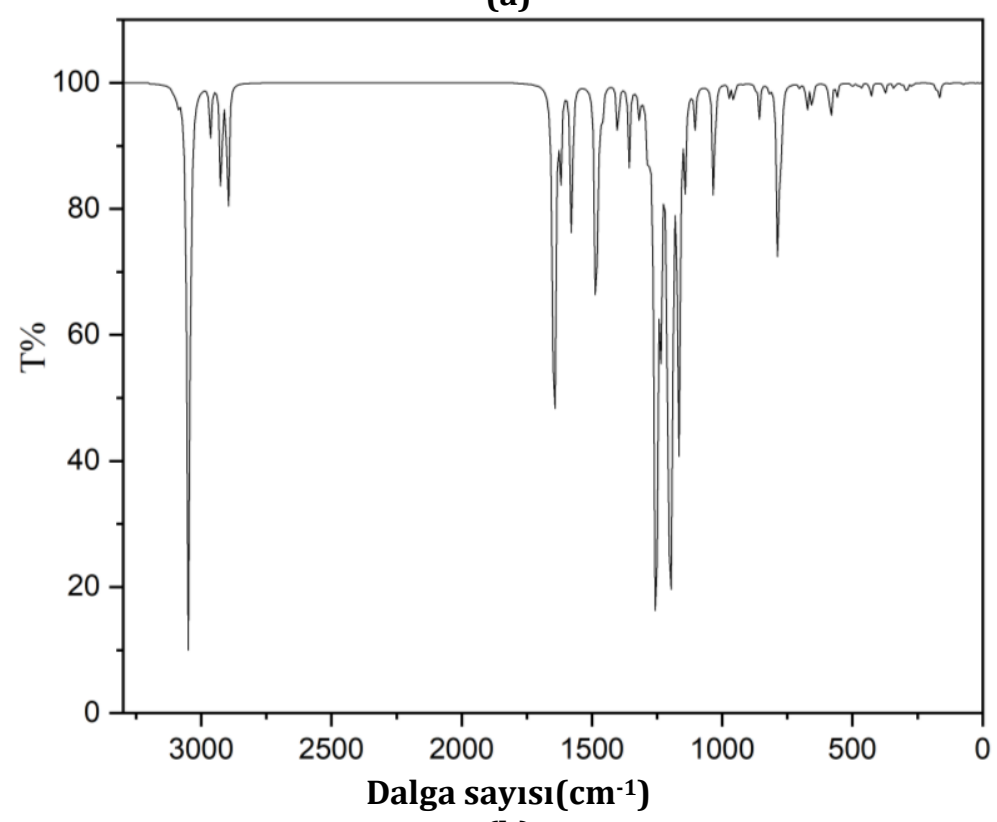

(b)

Şekil 8. Kristalin (a) Deneysel (b) Teoriksel IR spektrumları 


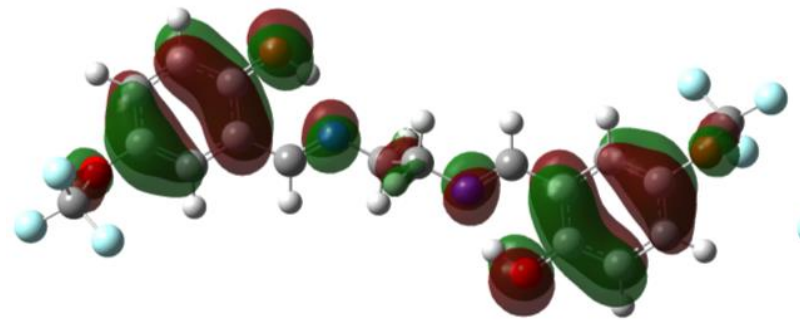

HOMO(-6.31 eV)

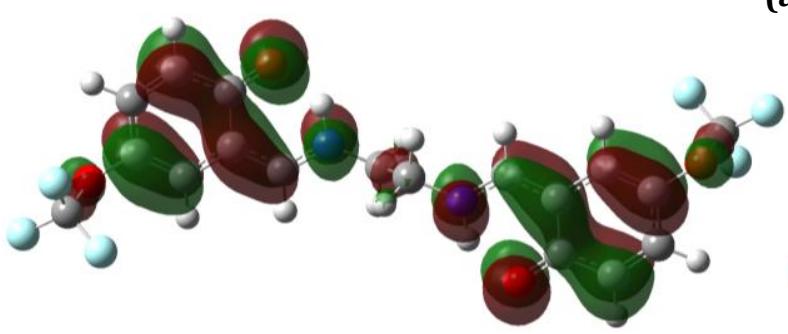

HOMO(-5.77 eV)

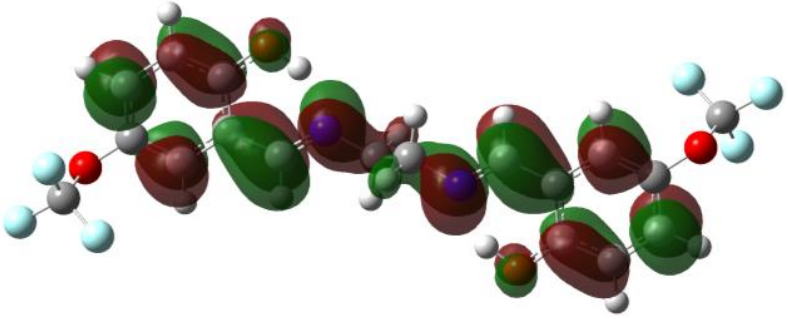

LUMO(-1.89 eV)

(a)

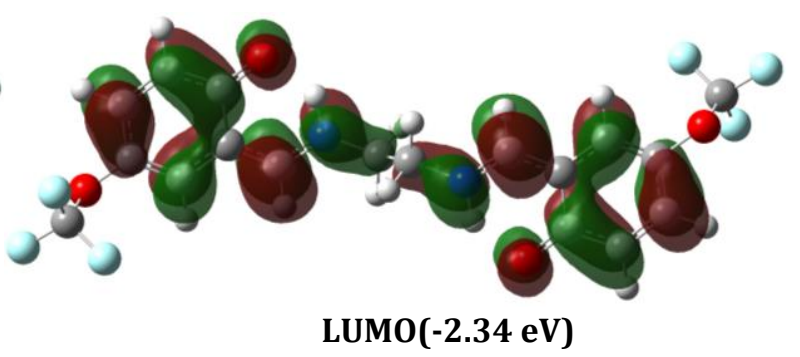

(b)

Şekil 9. Kristalin a) fenol-imin b) keto-amin formlarının Frontier orbitalleri ve enerjileri

Tablo 6. İki tautomer ve ZBA ligantlarının doking skorları ve reseptörün ARG410, HIS165 ve GLN318 (Şekil 11) ve HOMO enerjileri

\begin{tabular}{ccc}
\hline Ligantlar & Affinite (kcal/mol) & Eномо(eV) \\
\hline ZBA & -8.5 & -6.69 \\
Fenol-imin & -7.7 & -6.31 \\
Keto-amin & -7.3 & -5.77 \\
\hline
\end{tabular}

Ligantlar, reseptörlerin aktif bağlanma bölgesine zayıf kovalent olmayan etkileşimler ile daha belirgin olarak da hidrojen bağı, alkil ve $\pi$-alkil etkileşimleriyle bağlandığı görülmüştür. Şekil 10'da görüldüğü gibi reseptör ile referans ZBA ligantının 0 atomu ile reseptörün TYR421 aminoasiti ile 2.63 ve 2.72 , HIS165 aminoasiti ile 2.63, THR374 aminoasiti ile 2.47 ve 2.30 GLN318 aminoasiti ile 2.24 ve LEU373 aminoasiti ile $2.88 \AA$ Azunluğunda hidrojen bağları yapmaktadır. Fenol-imin ligantının $\mathrm{O}$ ve $\mathrm{F}$ atomları, keto-amin ligantının da $\mathrm{O}$ ve $\mathrm{F}$ atomları ise reseptörün THR374 ve ARG410 aminoasitleri ile hidrojen bağı etkileșimleri yaptığı gözlenmiştir (Şekil 12). Fenolimin ligantının Tablo 6'da görüldüğü gibi hesaplanan bağlanma affinitelerine (DScore) göre referans ligantına (ZBA) yakın değer verdiği görülmüștür. Sonuç olarak, iki tautomer ligantın, 2RKV hedef yapısı için inhibitör adayı olabilecek moleküller olarak belirlenebileceği söylenebilir. Ayrıca Tablo 6'da ve literatürde de belirtildiği gibi $[34,36]$ yüksek HOMO enerji değeri yüksek doking skorunu ortaya çıkarmaktadır. Elde edilen bulgulardan, bu bileşiklerin 2RKV protein yapısı için biyolojik aktiviteye sahip, yeni potansiyel inhibitör bileşik adayları olabileceği ve in vitro çalışmaları için kullanılabileceği sonucu çıkarılabilir.
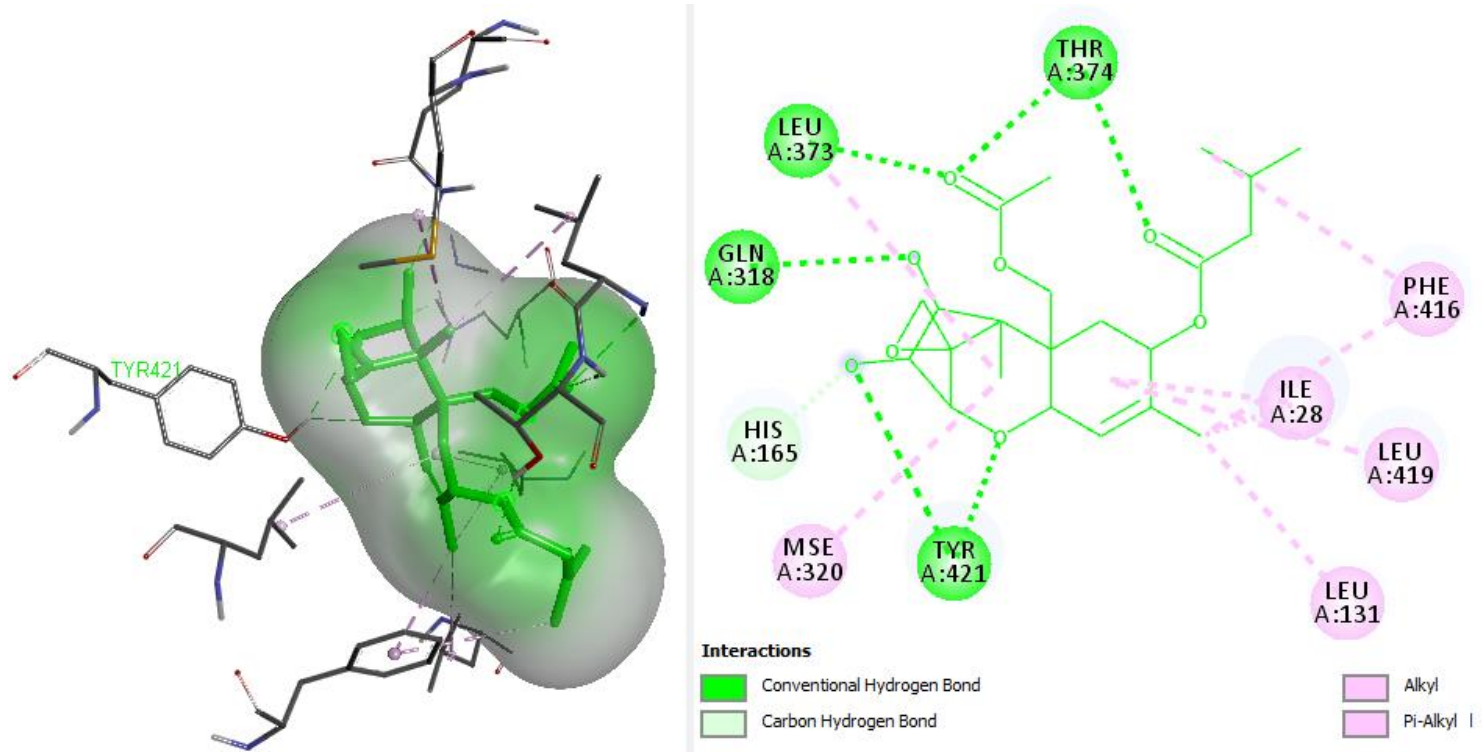

Şekil 10. ZBA ligantının 2RKV proteinin aktif bölgesindeki doking sonuçlarının 3D ve 2D gösterimi. 

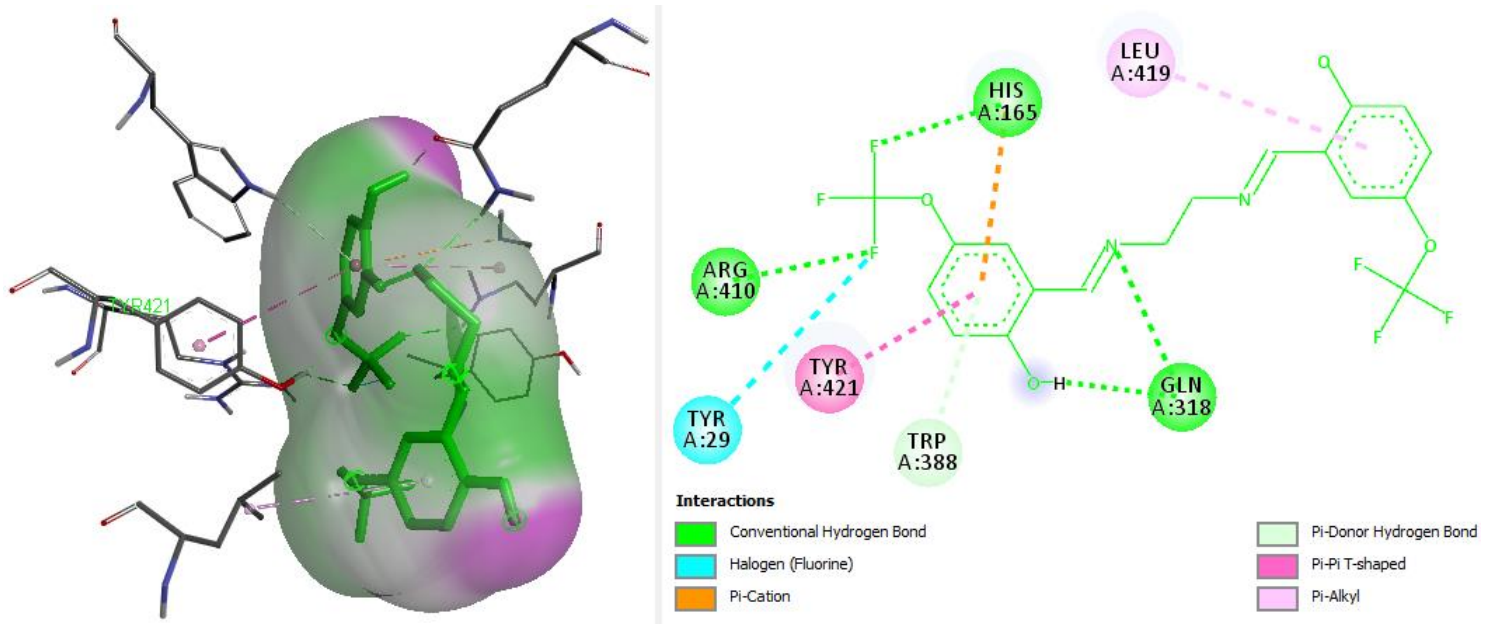

Şekil 11. Fenol-imin ligantının 2 RKV proteinin aktif bölgesindeki doking sonuçlarının 3D ve 2D gösterimi.
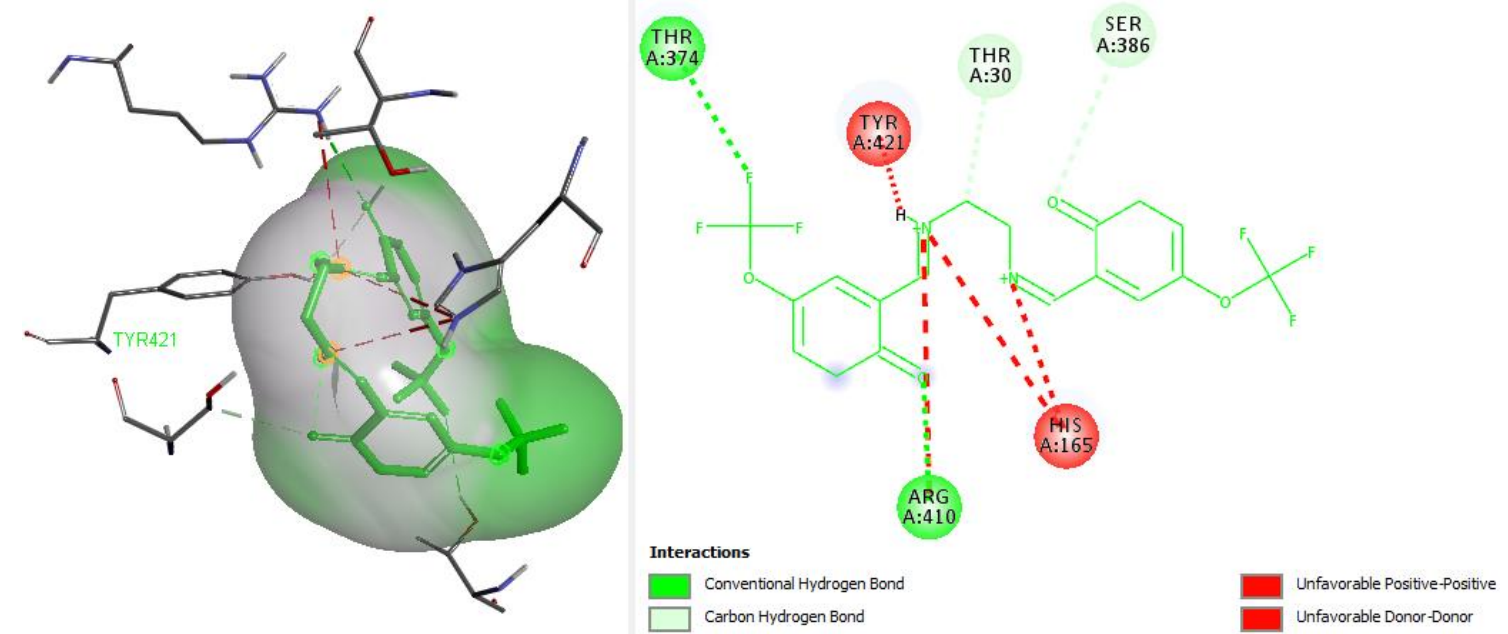

Şekil 12. Keto-amin ligantının $2 \mathrm{RKV}$ proteinin aktif bölgesindeki doking sonuçlarının 3D ve 2D gösterimi.

\section{Tartışma ve Sonuç}

Bu çalışmada, 2,2' - ((1E,1'E) - (ethan - 1,2 - dibis (azaneliden)) bis (methaneliden)) bis (4 (trifloromethoksi) fenol bileşiğinin yapısı, X-ışınları kırınımı ve IR spektroskopik yöntemleri ile aydınlatılmıștır. Yapılan deneysel çalıșmalarda fenolimin yapısının keto-amin yapısına göre daha kararlı olduğu belirlenmiştir. Teorik hesaplamalarda da yine fenol-imin formunun daha kararlı olduğu görülmüștür. IRC hesaplama sonucunda fenol-imin formunun toplam enerjisi -851,8465364 a.u. ve ketoamin formunun toplam enerjisi ise $-851,8396259$ olarak hesaplanmıştır. HOMO-LUMO enerji farkının fenol-imin formu için $4.42 \mathrm{eV}$, keto-amin için ise 3.43 $\mathrm{eV}$ çkmıștır. Fenol-imin formuna ait bu enerji değerinin keto-amin formuna göre daha küçük çıkması, yapısının daha kararlı olduğunu göstermektedir [32]. Bileşiğin kararlı yapısının ve yapisal parametrelerinin teorik olarak hesaplanmasindan sonra molekül için mümkün bağlanma modelleri ve konformasyonlarını elde etmek için doking simülasyon işlemi uygulanmıştır. Elde edilen sonuçlar, fenol-imin formunun 2RKV protein yapısı ile olumlu etkileşimler yaptığı ve yeni potansiyel inhibitör bileşik adayı olabileceğini göstermiştir. Fenol-imin formunun doking skoru -7.7 $\mathrm{kcal} / \mathrm{mol}$ ve HOMO enerji değeri $-6.31 \mathrm{eV}$, keto-amin formunun ise bu değerleri sırasıyla, $-7.3 \mathrm{kcal} / \mathrm{mol}$ ve $5.77 \mathrm{eV}$ olarak bulunmuştur. Sonuç olarak, doking skoru ile ligantların HOMO enerjileri arasında literatürde de belirtildiği gibi $[34,36]$ bir ilișki kurulabileceği belirtilmiş olup HOMO enerjisi arttıkça doking skorunun da arttığı görülmüştür. Yapılan tüm bu çalıșmalar sonucunda fenol-imin formunun ketoamin formuna göre daha iyi sonuçlar verdiği gözlenmiştir.

\section{Teşekkür}

Bu çalışmada kullanılan hesaplama kaynakları Ulusal Yüksek Başarımlı Hesaplama Merkezi'nin (UHeM), < $\mathbf{5 0 0 5 1 7 2 0 1 8}$ > numaralı desteğiyle, sağlanmıştır.

\section{Kaynakça}

[1] Bharti, S.K., Nath, G., Tilak, R., Singh, S. 2010. Synthesis, anti-bacterial and anti-fungal activities of some novel Schiff bases containing 2, 4disubstituted thiazole ring. European journal of medicinal chemistry, 45 (2010) 651-660.

[2] Khedr, A.M. Marwani, H.M. 2012. Synthesis, spectral, thermal analyses and molecular modeling of bioactive $\mathrm{Cu}$ (II)-complexes with 1,3 , 4-thiadiazole Schiff base derivatives. Their catalytic effect on the cathodic reduction of 
oxygen. Int J Electrochem Sci, 7 (2012) 1007410093.

[3] Ayhan-Kılcıgil, G., Kus, C., Özdamar, E.D., Can-Eke, B. Iscan, M. 2007. Synthesis and antioxidant capacities of some new benzimidazole derivatives. Archiv der Pharmazie, 340 (2007) 607-611.

[4] O'Neil, M.J., Smith, A. Heckelman, P. 2001. The Merck Index, 13th edn. Merck \& Co. Inc, Whitehouse Station, NJ, 6596.

[5] Kus, C., Ayhan-Kilcigil, G. Eke, B.C. 2004. Synthesis and antioxidant properties of some novel benzimidazole derivatives on lipid peroxidation in the rat liver. Archives of pharmacal research, 27 (2004) 156.

[6] Dega-Szafran, Z., Kania, A., GrundwaldWyspiańska, M., Szafran, M. Tykarska, E. 1996. Differences between the $\mathrm{N} \cdot \mathrm{H} \cdot \mathrm{O}$ and $\mathrm{O} \cdot \mathrm{H} \cdot \mathrm{O}$ hydrogen bonds in complexes of 2, 6-dichloro-4nitrophenol with pyridines and pyridine $\mathrm{N}$ oxides. Journal of molecular structure, 381 (1996) 107-125.

[7] Filarowski, A., Koll, A., Karpfen, A. Wolschann, P. 2004. Intramolecular hydrogen bond in molecular and proton-transfer forms of Schiff bases. Chemical physics, 297 (2004) 323-332.

[8] Asiri, A., Badahdah, K. 2007. Synthesis of some new anils: part 1. Reaction of 2-hydroxybenzaldehyde and 2-hydroxynaphthaldehyde with 2-aminopyridene and 2-aminopyrazine. Molecules, 12 (2007) 1796-1804.

[9] Raczynska, E.D., Kosinska, W. 2005. Tautomeric Equilibria in Relation to Pi-Electron Delocalization. Chem. Rev. 105 (2005) 3561 -3612 .

[10] Seanger, W. 1994. Principles of Nucleic Acid Structure; Springer; New York, 1994.

[11] Reddy, K.H., Reddy, P.S. Babu, P.R. 2000 Nuclease activity of mixed ligand complexes of copper (II) with heteroaromatic derivatives and picoline. Transition metal chemistry, 25 (2000) 505-510.

[12] Yu, W., Jia, J., Gao, J., Han, L. Li, Y. 2015. Synthesis, characterization and third-order nonlinear optical properties of symmetrical ferrocenyl Schiff base materials. Chemical Physics Letters, 624 (2015) 47-52.

[13] Zarei, S.A., Piltan, M., 2015. Hassanzadeh, K., Akhtari, K. \& Cinčić, D. Synthesis, characterization, crystal structure and predicting the second-order optical nonlinearity of a new dicobalt (III) complex with Schiff base ligand. Journal of Molecular Structure, 1083 (2015) 8287.

[14] Zakerhamidi, M., Nejati, K., Sorkhabi, S.G. Saati, M. 2013. Substituent and solvent effects on the spectroscopic properties and dipole moments of hydroxyl benzaldehyde azo dye and related Schiff bases. Journal of Molecular Liquids, 180 (2013) 225-234.

[15] Brown, I., Leopold, D., Mohite, S., Sandreczki, T. 1995. Conducting thermoset polymers: A comparative study of Schiff base precursors with different end groups. Synthetic metals, 72 (1995) 269-274.

[16] Dhahagani, K., Kumar, S.M., Chakkaravarthi, G., Anitha, K., Rajesh, J., Ramu, A. Rajagopal, G. 2014. Synthesis and spectral characterization of Schiff base complexes of $\mathrm{Cu}$ (II), Co (II), Zn (II) and VO (IV) containing 4-(4-aminophenyl) morpholine derivatives: Antimicrobial evaluation and anticancer studies. Spectrochimica Acta Part A: Molecular and Biomolecular Spectroscopy, 117 (2014) 87-94.

[17] Hanif, M. Chohan, Z.H. 2013. Design, spectral characterization and biological studies of transition metal (II) complexes with triazole Schiff bases. Spectrochimica Acta Part A: Molecular and Biomolecular Spectroscopy, 104 (2013) 468-476.

[18] Güngör, Ö., Gürkan, P. 2014. Synthesis and characterization of higher amino acid Schiff bases, as monosodium salts and neutral forms. Investigation of the intramolecular hydrogen bonding in all Schiff bases, antibacterial and antifungal activities of neutral forms. Journal of Molecular Structure, 1074 (2014) 62-70.

[19] Bruker, A. 2008. APEX2, V2008. 6, SADABS V2008/1, SAINT V7. 60A, SHELXTL V6. 14. Bruker AXS Inc, Madison, Wisconsin, USA, (2008).

[20] Sheldrick, G.M. 2015. SHELXT-Integrated spacegroup and crystal-structure determination. Acta Crystallographica Section A: Foundations and Advances, 71 (2015) 3-8.

[21] Sheldrick, G.M. 2015. Crystal structure refinement with SHELXL. Acta Crystallographica Section C: Structural Chemistry, 71 (2015) 3-8.

[22] Dolomanov, O.V., Bourhis, L.J., Gildea, R.J., Howard, J.A. Puschmann, H. 2009. OLEX2: a complete structure solution, refinement and analysis program. Journal of Applied Crystallography, 42 (2009) 339-341.

[23] Frisch, M., Trucks, G., Schlegel, H.B., Scuseria, G., Robb, M., Cheeseman, J., Scalmani, G., Barone, V., Mennucci, B., Petersson, G. 2009. Gaussian 09, revision a. 02, gaussian. Inc, Wallingford, CT, 200 (2009).

[24] Becke, A.D. 1993. Density-functional thermochemistry. III. The role of exact exchange. The Journal of chemical physics, 98 (1993) 56485652.

[25] Lee, C., Yang, W. Parr, R.G. 1988. Development of the Colle-Salvetti correlation-energy formula into 
a functional of the electron density. Physical review B, 37 (1988) 785 .

[26] Foresman, J.B., Frisch, A. 1996. Exploring chemistry with electronic structure methods: a guide to using Gaussian.

[27] Dennington, R., Keith, T., Millam, J., Eppinnett, K., Hovell, W.L. Gilliland, R. 2009. GaussView. Version.

[28] Dallakyan, S., Olson, A.J. 2015. Small-molecule library screening by docking with PyRx. Chemical Biology: Springer; 2015. p. 243-250.

[29] Karakurt, T., Cukurovali, A., Subasi, N.T., Onaran, A., Ece, A., Eker, S. Kani, I. 2018. Experimental and theoretical studies on tautomeric structures of a newly synthesized 2, 2'(hydrazine-1, 2diylidenebis (propan-1-yl-1-ylidene)) diphenol. Chemical Physics Letters, 693 (2018) 132-145.

[30] Chantrapromma, S., Jansrisewangwong, P. Fun, H.-K. 2010. (1E, 2E)-1, 2-Bis [1-(2methoxyphenyl) ethylidene] hydrazine. Acta Crystallographica Section E: Structure Reports Online, 66 (2010) o2994-o2995.

[31] Fun, H.-K., Jansrisewangwong, P., Karalai, C. Chantrapromma, S. 2011. (1E, 2E)-1, 2-Bis [1-(3chlorophenyl) ethylidene] hydrazine. Acta Crystallographica Section E: Structure Reports Online, 67 (2011) o3424-o3424.

[32] Karakurt, T. 2018. Investigation of the molecular structure of 4-(3-methyl-3-phenylcyclobutyl)-2[2-(3-methylbenzylidene) hydrazinyl] thiazole in the gas and solid phases. Acta Crystallographica
Section C: Structural Chemistry, 74 (2018) 15021508.

[33] Karakurt, T., Cukurovali, A., Subasi, N.T. Kani, I. 2016. Molecular structure and computational studies on 2-((2-(4-(3-(2, 5-dimethylphenyl)-3methylcyclobutyl) thiazol-2-yl) hydrazono) methyl) phenol monomer and dimer by DFT calculations. Journal of Molecular Structure, 1125 (2016) 433-442.

[34] Tamer, Ö., Avcl, D. Atalay, Y. 2014. Quantum chemical characterization of N-(2hydroxybenzylidene) acetohydrazide (HBAH): A detailed vibrational and NLO analysis. Spectrochimica Acta Part A: Molecular and Biomolecular Spectroscopy, 117 (2014) 78-86.

[35] Atkins, P. Paula J. 2006. Atkins' physical chemistry. New York: WH Freeman and Company; 2006.

[36] Karakurt, T. 2018. Tiyadiazol Halkası İçeren "5(2-Kloro-6-Florobenziltiyo)-1, 3, 4-Tiyadiazol2Amin"Tek Kristalinin Moleküler Yapısının Deneysel ve Teorik Yöntemlerle İncelenmesi. Akü Femübid, 18 (2018) 1158-1166.

[37] Er, M., Ergüven, B., Tahtaci, H., Onaran, A., Karakurt, T. Ece, A. 2017. Synthesis, characterization, preliminary SAR and molecular docking study of some novel substituted imidazo $[2,1-b][1,3,4]$ thiadiazole derivatives as antifungal agents. Medicinal Chemistry Research, 26 (2017) 615-630. 